Document downloaded from:

http://hdl.handle.net/10251/101799

This paper must be cited as:

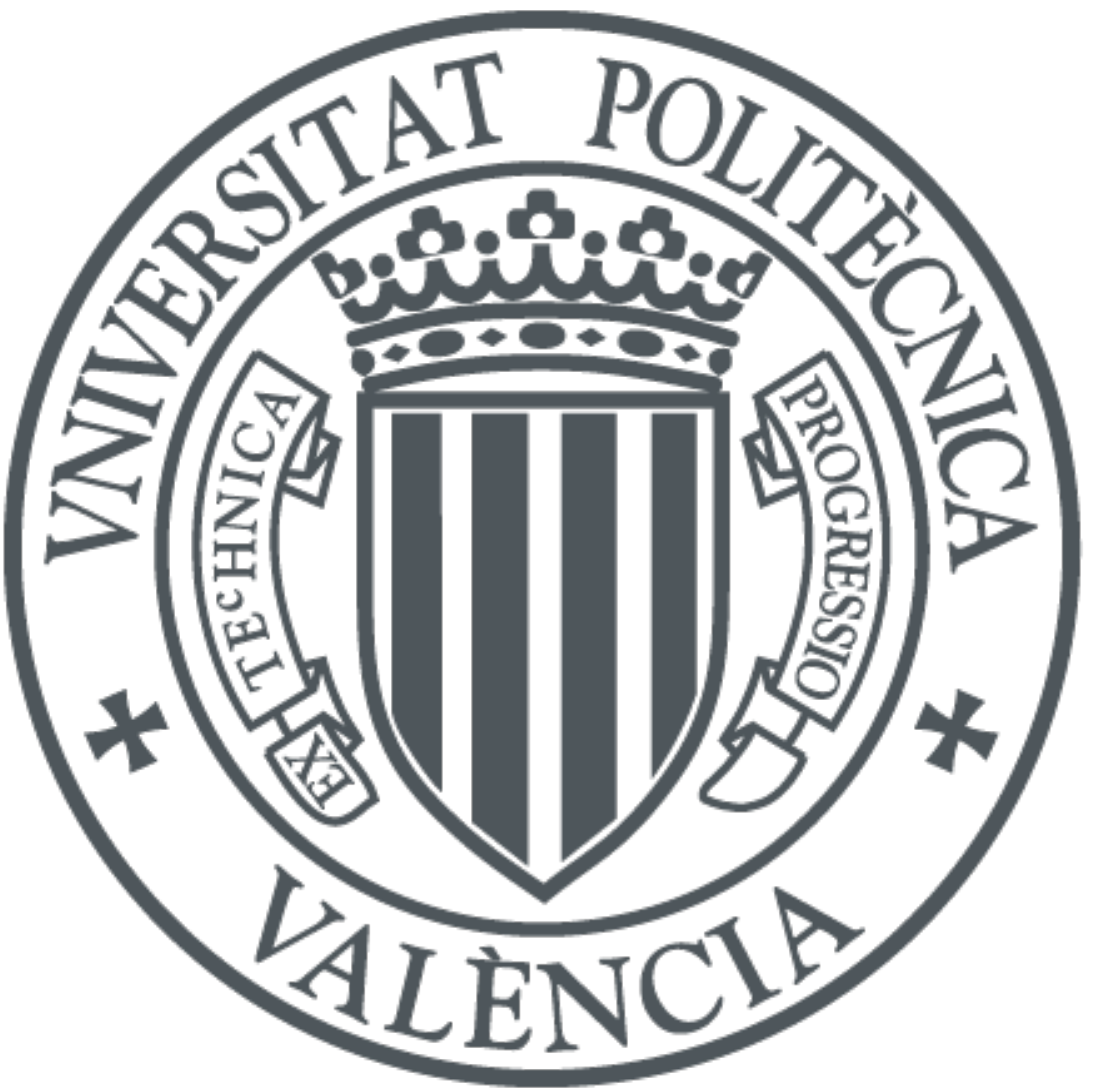

The final publication is available at

https://doi.org/10.1007/978-3-319-65151-4_64

Copyright Springer

Additional Information 


\title{
Conceptual Framework for Managing Uncertainty in a Collaborative Agri-Food Supply Chain Context
}

\author{
Ana Esteso ${ }^{1}$, MME Alemany ${ }^{1}$, Ángel Ortiz \\ ${ }^{1}$ Research Centre on Production Management and Engineering (CIGIP). Universitat \\ Politècnica de València. Camino de Vera $\mathrm{S} / \mathrm{N}, 46002$ València, Spain \\ aneslva@doctor.upv.es, \{mareva, aortiz\}@cigip.upv.es
}

\begin{abstract}
Agri-food supply chains are subjected to many sources of uncertainty. If these uncertainties are not managed properly, they can have a negative impact on the agri-food supply chain (AFSC) performance, its customers, and the environment. In this sense, collaboration is proposed as a possible solution to reduce it. For that, a conceptual framework (CF) for managing uncertainty in a collaborative context is proposed. In this context, this paper seeks to answer the following research questions: What are the existing uncertainty sources in the AFSCs? Can collaboration be used to reduce the uncertainty of AFSCs? Which elements can integrate a CF for managing uncertainty in a collaborative AFSC? The CF proposal is applied to the weather source of uncertainty in order to show its applicability.
\end{abstract}

Keywords: Agri-food Supply Chains; Collaboration; Uncertainty; Conceptual Framework,

\section{Introduction}

The term "agri-food supply chain" (AFSC) has been defined as a set of activities necessary to bring agricultural products "from the farm to the fork" $[1,2,3,4]$. Therefore, both vegetable and animal-based products are produced in and distributed by AFSCs [5].

AFSCs are subjected to many sources of uncertainty. If these sources of uncertainty are not managed properly, not only the AFSC performance may be negatively affected but also the customers service levels and the environment would be also affected. In this sense, collaboration is proposed as a possible solution to reduce this negative impact. For that, a conceptual framework $(\mathrm{CF})$ for managing uncertainty in a collaborative context is proposed. In this context, this paper seeks to answer the research questions (RQ):

RQ1. What are the existing sources of uncertainty in the AFSCs?

RQ2. Can collaboration be used to reduce the uncertainty of AFSCs?

RQ3. Which elements can integrate a CF for managing uncertainty in a collaborative AFSC? 
Since horticulture sector has received the least attention in the literature and the production processes of meat and horticulture sectors are extremely different, this paper focuses on the crop-based AFSCs.

Therefore, the main contributions of this paper are the identification of the existing sources of uncertainty in crop-based AFSC, and the proposal of a CF for reducing these uncertainties through the collaboration of the AFSC members. For that, literature search related to collaboration in AFSC is carried out within well-known databases, such as Springer, Elsevier, and many others. To the best of our knowledge there are few papers dealing the collaboration as a tool for reducing uncertainty in AFSCs and, some authors have stated that more research on supply chain collaboration is needed in order to cope uncertainty in the agricultural sector [2], [6].

The remainder of this paper is organized as follows. In Section 2, the existing sources of uncertainty in crop-based AFSC are detailed. A reflection of the impact of collaboration over these uncertainties is performed in Section 3. As a result, the CF for managing uncertainty in a collaborative AFSC context is proposed in Section 4. Finally, conclusions are exposed in the last section.

\section{Crop-Based AFSC Sources of Uncertainty}

Crop-based AFSCs are subjected to many sources of uncertainty which are mainly related to inherent characteristics of the agri-food sector. If these sources of uncertainty are not managed properly, they can have a negative impact on the AFSC performance, its customers, and the environment. However, if the level of uncertainty is reduced, the supply chain performance will be improved. Therefore, the aim of this section is to answer the Research Question: What are the existing sources of uncertainty in the AFSCs?

Supply chains uncertainty commonly refers to situations in which decisionmakers have not enough information about objectives to make decisions; have a vague idea of the supply chain and/or its environment; are not able to predict the impact of decisions on supply chain's performance; or lacks effective control actions[7], [8].

According to [9], we are in the realm of decision making under uncertainty if it is ignored the probability of occurrence of the possible specific outcomes. In addition, when making a decision under uncertainty, the decision maker may or may not know the different outcomes that can occur [10].

This paper proposed a CF (Fig.1) for the AFSC sources of uncertainty classification. This framework has been based on the CF in [11] where the SC uncertainties are divided into supply, demand, process and planning \& control uncertainties. This classification has been extended by adding the sources of uncertainty related to products and to environment. For the purpose of this paper, although the sources of uncertainty are interrelated, we consider it more appropriate to group them into different categories to which they make reference. The categories proposed for the crop-based AFSC sources of uncertainty are product, process, market and, environment. 




Fig. 1. Conceptual framework for the uncertainty sources of crop-based AFSCs

The identified sources of uncertainty related to crop-based AFSC products are:

- Uncertainty on shelf-life. The product shelf-life is the time during which the product losses its tacit initial characteristics becoming a non-value item for customers [12]. Then, the product shelf-life and physical state are not necessarily interrelated since many products deteriorate after the end of their shelf-life. Hence, product shelf-life may reflect its marketable life [13]. As the shelf-life of a product is the period of time during which quality losses do not exceed a tolerated level, the product's time and temperature history must be known; if not, the shelf-life is uncertain [14].

- Uncertainty on deterioration. Deterioration of products is the process where items decay, get damaged or spoiled, being impossible to use them for their original purpose [15]. It can be classified as age-dependent on-going deterioration and age-independent on-going deterioration [13]. Agri-food products are goods subject to age-dependent on-going deterioration. Most authors talk about constant or probabilistic deterioration rates, however, it can be considered as uncertain as the quantity and quality deterioration over time can be unknown.

- Uncertainty on lack of homogeneity of products. Agri-food sector is characterized by the lack of homogeneity of the product, so the products obtained after harvesting differ in some attributes (maturity, color, bacterial level, various size and weights of items...) that are relevant for customers because they require to be served with homogeneous units of the same product [16]. Correct handling of the lack of homogeneity in the product and its inherent uncertainty is important to reduce and avoid inefficiencies of the supply chain and improve customer service level [16].

- Uncertainty on food quality. Food quality is the combination of food features that establishes the customer satisfaction and compliance to legal standards [17]. It usually refers not only to the physical properties of food products, but also to the customer perception of it [18]. Product quality is characterized by properties such as texture, taste, flavor, smell, color, presence of pathogens, 
toxins or hormones... [17], [18], [19]. Some of these attributes can be easy to measure while others are subject to customer's perception, making its assessment very challenging (e.g., taste) [19]. Then, there is uncertainty in food quality as it is subjective so it cannot be certainly measured.

- Uncertainty on food safety. Food safety generally refers to the prevention of illnesses resulting from the consumption of contaminated food [18]. There is a need to guarantee food safety as the customer's trust and market acceptance depend on it [20]. Since food safety cannot be measured and guaranteed in the final product, it can be considered an uncertain factor.

The uncertainty sources related to crop-based AFSC processes are:

- Uncertainty on harvesting yield. The crops' ripening process and the capability of performing harvesting operations are highly influenced by land and weather conditions, so harvesting yield worsens if part of the crops cannot be collected at the moment of adequate ripeness [21]. Therefore, harvesting yield is usually an uncertain factor in terms of product quantity, quality and harvesting time. This is related to the uncertainty in supply of raw material as the SC stage after harvesting will not know the quantity, quality and time of the supply until it is received.

- Uncertainty on supply lead time. The lead time is the time taken from the beginning of a process to its end. AFSCs are characterized by their long supply lead times as many crops spend from six to nine months since their planting until their harvesting [1], [21]. Supply lead time can be considered an uncertain factor as the needed time for crops to grow is generally long, seasonal and, weather and yield dependent [22].

- Uncertainty on resource needs. Resources needed for harvesting, which can be established by the number, capacity and productivity of machines and laborers, are limited [21]. Given the uncertainty on the harvesting quantity, the resource needs cannot be known until the harvest is done.

- Uncertainty on production. Production depends on the raw materials received, as their quantity, quality and characteristics are not known a priori. This uncertainty provokes the need of having alternative recipes in order to produce the same final product [5], [11].

The uncertainty sources related to crop-based AFSC markets are:

- Uncertainty on demand. Demand of agri-food products is not only related to product and quantity, but also to the quality and safety requirements of the customer and factors such as remaining shelf-life of the product. Demand uncertainty reflects the uncertainty of customer demand for a product [23]. Natural causes as seasonality and weather as well as promotional activities can cause variability in customer demand, creating uncertainty [1].

- Demand can be dependent of the remaining shelf-life of products, inventory level, time, market trends or price; demand can follow a distribution function or it can be completely unknown [15].

- Uncertainty on market prices. Market prices are volatile and keep changing across the day [24]. The variability of prices in the different stages of supply chains are caused by dynamic factors such as the price of substitute products, inflation, production costs, import, export, customer demands, seasonality, product availability and the supply-demand balance [25]. 
The uncertainty sources related to crop-based AFSC environment are:

- Uncertainty on weather and land conditions. Weather conditions, such as temperature and precipitation, mainly affect the harvesting yield and activity. The harvesting process is complex as it dispose of limited resources and, it gets even more complex when considering the uncertainty related to weather conditions [21]. Weather and land conditions cannot be known with certainty.

- Uncertainty on pests and diseases. Agri-food products can be contaminated by pests and biotic hazards such as bacteria, viruses and other emerging pathogens [26]. Yield losses can be reduced by protecting the crops from various diseases with pesticides [27]. Pest and disease infestations are random factors that could be controlled by management [28].

- Uncertainty on regulations. The regulatory framework of the agri-food sector, comprised by public and private regulations dealing with food quality and safety, set the diverse requirements for tracking and tracing capabilities [20]. There is uncertainty on the appearance of new, more stringent, regulations.

It is worth mentioning that different relationships exist among the sources of uncertainty described. For instance, uncertainty on weather implicitly originates uncertainty in harvesting yields.

\section{Impact of Collaboration on Crop-Based AFSC}

Supply chains have been defined as goal-oriented networks in which their partners intensively collaborate with each other towards a common goal [29]. Then, the collaboration on supply chain means that two or more chain members actively and jointly work (spanning the organizations boundaries) for fulfilling and satisfying consumers' needs [2]. With collaboration, stakeholders are able to share their assets and capabilities so they can reduce the uncertainty, share the risk and cost, and serve customers at the right time, quantity, and quality without disregarding the interest of other stakeholders [30].

Collaboration is a powerful tool to improve the AFSCs performance. However, its implementation is complex as existing barriers potentially deteriorate collaboration among companies, e.g. the incompatibility of information exchange systems, the big quantity of enterprises making up a supply chain or the lack of trust between the parties. Despite this, collaboration is becoming more a necessity than an option [2].

The collaboration concept can be categorized into three interrelated dimensions (Fig. 2): information sharing, decision synchronization, and incentive alignment [31]. These three dimensions represent different levels of collaboration so that for changing from a level of collaboration to a superior one it is necessary to ensure the proper functioning of the previous collaborative levels. Different benefits and risks of collaboration can exist depending on the Supply Chain Activities [2]. According to these authors [30], the information sharing consists in capturing and disseminating timely information that is relevant for decision makers when planning and controlling supply chain operations; the decision synchronization consists in making planning 
and operational decisions jointly; and, the incentive alignment consists of the degree of sharing costs, risks and benefits between supply chain members.

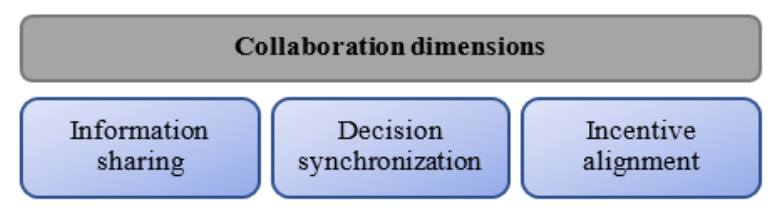

Fig. 2. Collaboration dimensions

Then, is it needed the collaboration to reduce the uncertainty on AFSCs? Supply chain collaboration can be necessary for various reasons. Collaboration is needed in AFSC for minimizing its costs, increasing the profits, ensuring the quality, and gaining customers trust [30]. Collaboration is also needed in the agri-food sector as AFSC are competing against other AFSC and single companies are not competing with each other anymore [32]. Another reason for collaborating in AFSC is given by the increased public pressure for transparency, traceability and "due diligence" throughout the AFSC due to the combination of social concern about food safety and the recent food crises [2]. These crises have emphasized the close interdependencies between AFSC actors and their need of cooperation in order to be a competitive AFSC and to ensure the meet of the customers' requirements related to food quality and safety [20].

However, an additional reason for applying collaboration in AFSC is the huge amount of sources of uncertainty that impact over its performance and which are mainly generated by the lack of information through the AFSC. Uncertainty can be reduced by supply chain collaboration [30], [32]. Sharing information reduces uncertainty as decision-makers dispose reliable data to conduct the decision making process (e.g. if the AFSC members share information about the traceability of the product, the food safety of the product would be guaranteed). Making joint decisions reduces uncertainty as decision-makers of two AFSC stages have all the information to make more appropriate decisions for both parts (e.g. farmers and producers decide jointly when to harvest, then the used capacities of both stakeholders can be optimized). The incentive alignment reduces uncertainty as the motivation to obtain maximum benefits make the stakeholders share high quality information (e.g. stakeholders could establish an equitable distribution of profits between them in order to reduce the share of profits).

Collaboration not only provide benefits, but also risks. The main risks in collaboration are [2]: the risk of failure (loss of the investment made, loss of time, and business plans delay or renouncement); potential interdependence between companies; increasing operational complexity and integration technology. 


\section{Conceptual Framework for Uncertainty Management through Collaboration in AFSCs}

In this section a conceptual framework (CF) to manage the inherent uncertainty sources of AFSCs through collaboration is proposed. Then, this CF tries to give and answer to the last research question: What elements can be considered for managing uncertainty by means collaboration in AFSC? The proposed elements for this CF are grouped into four blocks for AFSCs (Fig.3): Sources of uncertainty, Management, Collaboration and Collaboration Impact. In the following, each element is described.

- AFSC Uncertainty Sources: in this block, the sources of uncertainty to be studied in the CF is indicated and the uncertainty sources affected by the studied one are identified.

- Sources of uncertainty studied: the source of uncertainty to be managed is selected from the CF for the sources of uncertainty of crop-based AFSCs (Section 2).

- Other Uncertainty Sources affected: Because different sources of uncertainty are not independent, the strongest relationship between the uncertainties studied and the other ones should be identified.

- AFSC Management: in this block, the activities and stakeholders influenced by the studied sources of uncertainty are identified.

- Management activities influenced by the sources of uncertainty selected and the others affected by it should be determined.

- Involved stakeholders related to the above activities should be determined with the aim of identifying the possible AFSC members for collaboration: farmers, processors, distributors, retailers and other stakeholders (NGO's, government...) [5].

- AFSC Collaboration: in this block, the collaboration dimensions to be employed to reduce the studied sources of uncertainty and their related practices are identified.

- Collaboration dimension: the different collaboration dimensions (information sharing, decision synchronization, and incentive alignment) are detailed.

- Collaboration practices: different collaboration practices can be adopted in order to establish the collaboration between stakeholders. Each collaboration practice will have a different impact on the AFSC.

- Impact on AFSC: the benefits and risks produced by the collaboration practice proposed are identified. For each collaboration practice could be made qualitatively and/or quantitatively:

- Benefits of each collaboration practice should be detailed (assessed) on the AFSC characteristics and sources of uncertainty.

- Risks for each collaboration practice should also be taken into account when analyzing the possible collaboration practice to be implemented.

When making the decision of which collaboration dimension to implement for reducing an uncertainty, the $\mathrm{CF}$ can be applied to collect information of the benefits, risks and other issues related to each collaboration practice. Although the highest 
collaboration level could offer more benefits in reducing uncertainty, decision-makers have to make a balance between the level of uncertainty and resources consumption they are ready to assume and the benefits they are obtaining in return. This reason justifies the application of the proposed $\mathrm{CF}$ to decide the collaborative practice to implement by collecting the needed information to make an adequate decision.
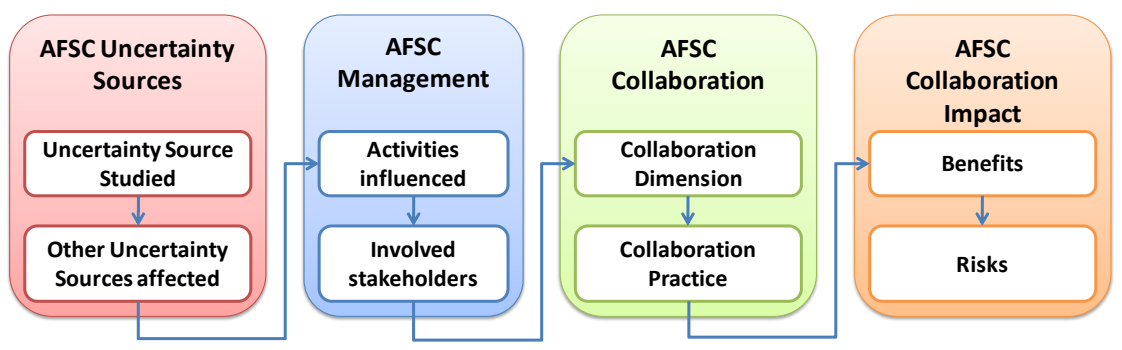

Fig. 3. Conceptual framework for managing uncertainty in a collaborative AFSC context

An example of how to use the proposed $\mathrm{CF}$ for identifying the consequences/impact of the information sharing collaboration dimension on the weather uncertainty is illustrated in Table 1. By developing the same table for the two remaining collaboration levels the user would be able to decide which collaboration level is the most appropriate to his case. The objective of this example is not to show the whole decision process, but to illustrate the way to use the CF.

Table 1. Example for the conceptual framework completion.

\begin{tabular}{|l|l|}
\hline CF Elements & Application \\
\hline $\begin{array}{l}\text { Uncertainty Source } \\
\text { Studied }\end{array}$ & Weather \\
\hline $\begin{array}{l}\text { Other Uncertainty } \\
\text { Sources affected }\end{array}$ & $\begin{array}{l}\text { Harvesting yield, food quality and indirect effects related with } \\
\text { changes in the distribution of pests and diseases. }\end{array}$ \\
\hline Activities influenced & $\begin{array}{l}\text { Planning of harvesting operations (planting and harvesting } \\
\text { scheduling, effective resource management among competing } \\
\text { crops), Procurement }\end{array}$ \\
\hline Involved Stakeholders & Seed Suppliers, Pesticides Suppliers, Farmers and Producers. \\
\hline Collaboration Dimension & Information Sharing \\
\hline Collaboration Practice & $\begin{array}{l}\text { Sharing information among involved stakeholders on rainfall, } \\
\text { water level in soil, use of pesticides and fertilizers and driving } \\
\text { lanes of farm machines. }\end{array}$ \\
\hline Benefits & $\begin{array}{l}\text { Predict the harvesting yield takes an input to multiple process, } \\
\text { Optimize the use of pesticides, fertilizers and water. }\end{array}$ \\
\hline Risks & $\begin{array}{l}\text { Technological risks for the necessity of sensors and properly } \\
\text { information technologies. }\end{array}$ \\
\hline
\end{tabular}




\section{Conclusions}

This paper has identified the existing sources of uncertainty in crop-based AFSC. A $\mathrm{CF}$ is proposed where these uncertainties are classified into product, process, market and environment characteristics. If these uncertainties are not managed properly, they can have a negative impact on the AFSC performance. As a solution, collaboration has been proposed as a possible solution to minimize this impact. To conclude, a CF to manage uncertainty in a collaborative AFSC context is designed. After completing this $\mathrm{CF}$, it could be used by researchers and practitioners to determine the best way to reduce the studied uncertainty sources that affect their supply chains.

Acknowledgments. The first author acknowledges the partial support of the Program of Formation of University Professors of the Spanish Ministry of Education, Culture, and Sport (FPU15/03595). The other authors acknowledge the partial support of the Project 691249, RUC-APS: Enhancing and implementing Knowledge based ICT solutions within high Risk and Uncertain Conditions for Agriculture Production Systems, funded by the EU under its funding scheme H2020-MSCA-RISE-2015"

\section{References}

1. Taylor, D.H., Fearne, A.: Towards a framework for improvement in the management of demand in agri-food supply chains. Supply Chain Manag. Int. J. 11, 379--384 (2006)

2. Matopoulos, A., Vlachopoulou, M., Manthou, V., Manos, B.: A conceptual framework for supply chain collaboration: empirical evidence from the agri-food industry. Supply Chain Manag. Int. J. 12, 177--186 (2007)

3. Ahumada, O., Villalobos, J.R.: Application of planning models in the agri-food supply chain: A review. Eur. J. Oper. Res. 196, 1--20 (2009)

4. Tsolakis, N.K., Keramydas, C.A., Toka, A.K., Aidonis, D.A., Iakovou, E.T.: Agrifood supply chain management: A comprehensive hierarchical decision-making framework and a critical taxonomy. Biosyst. Eng. 120, 47--64 (2014)

5. van der Vorst, J.G., Da Silva, C.A., Trienekens, J.H.: Agro-industrial supply chain management: Concepts and applications. FAO (2007)

6. Borodin, V., Bourtembourg, J., Hnaien, F., Kabadie, N.: Handling uncertainty in agricultural supply chain management: A state of the art. Eur. J. Oper. Res. 254, 348--359 (2016)

7. van der Vorst, J.G.A.J., Beulens, A.J.M.: Identifying sources of uncertainty to generate supply chain redesign strategies. Int. J. Phys. Distrib. Logist. Manag. 32, 409--430 (2000)

8. Klosa, E.: A concept of models for supply chain speculative risk analysis and management. J. Econ. Manag. 12, 45--59 (2013).

9. Samson, S., Reneke, J.A., Wiecek, M.M.: A review of different perspectices on uncertainty and risk and an alternative modeling paradigm. Reliab. Eng. Syst. Saf. 94, 558--567 (2009)

10.Backus, G.B.C., Eidman, V.R., Dijkhuizen, A.A.: Farm decision making under risk and uncertainty. Neth. J. Agric. Sci. 45, 307--328 (1997)

11.van der Vorst, J.G.: Effective food supply chains; Generating, modelling and evaluating supply chain scenarios. (2000)

12.Amorim, P., Günther, H.O., Almada-Lobo, B.: Multi-objective integrated production and distribution planning of perishable products. Int. J. Prod. Econ. 138, 89--101 (2012) 
13.Amorim, P., Meyr, H., Almeder, C., Almada-Lobo, B.: Managing perishability in production-distribution planning: a discussion and review. Flex. Serv. Manuf. 25, 389--413 (2013)

14.Costa, C., Antonucci, F., Pallottino, F., Aguzzi, J., Sarria, D., Menesatti, P.: A review on agri-food supply chain traceability by means of RFID technology. Food Bioprocess Technol. 6, 353--366 (2013)

15.Pahl, J., Voss, S.: Integrating deterioration and lifetime constraints in production and supply chain planning: A survey. Eur. J. Oper. Res. 238, 654--674 (2014)

16.Grillo, H., Alemany, M.M.E., Ortiz, A.: A review of Mathematical models for supporting the order promising process under Lack of Homogeneity in Product and other sources of uncertainty. Comput. Ind. Eng. 91, 239--261 (2016)

17.Zwietering, M.H., van't Riet, K.: Modelling of the quality of food: optimization of a cooling chain. In: Management studies and the agri-business: Management of Agri-chains, pp- 108-117, Wageningen, The Netherlands (1994)

18.Akkerman, R., Farahani, P., Grunow, M.: Quality, safety and sustainability in food distribution: a review of quantitative operations management approaches and challenges. Spectr. 32, 863--904 (2010)

19.Apaiah, R.K., Hendrix, E.M.T., Meerdink, G., Linnemann, A.R.: Qualitative methodology for efficient food chain design. Trends Food Sci. Technol. 16, 204--214 (2005)

20.Lehmann, R.J., Reiche, R., Schiefer, G.: Future internet and the agri-food sector: State-ofthe-art in literature and research. Comput. Electron. Agric. 89, 158--174 (2012)

21.Kusumastuti, R.D., van Donk, D.P., Teunter, R.: Crop-related harvesting and processing planning: A review. Int. J. Prod. Econ. 174, 76--92 (2016)

22.Dreyer, H.C., Strandhagen, J.O., Hvolby, H.H., Romsdal, A., Alfnes, E.: Supply chain strategies for speciality foods: a Norwegian case study. Prod. Plan. Control 27, 878--893 (2016)

23.Baghalian, A., Rezapour, S., Farahani, R.Z.: Robust supply chain network design with service level against disruptions and demand uncertainties: A real-life case. Eur. J. Oper. Res. 227, 199--215 (2013)

24.Aggarwal, S., Srivastava, M.K.: Towards a grounded view of collaboration in Indian agrifood supply chains: A qualitative investigation. Br. Food J. 115, 1085--1106 (2016)

25.Teimoury, E., Nedaei, H., Ansari, S., Sabbaghi, M.: A multi-objective analysis for import quota policy making in a perishable fruit and vegetable supply chain: A system dynamics approach. Comput. Electron. Agric. 93, 37--45 (2013)

26.Opara, L.U.: Traceability in agriculture and food supply chain: a review of basic concepts, technological implications, and future prospects. J. Food Agric. Environ. 1, 101--106 (2003)

27.Kruize, J.W., Wolfert, S., Goense, D., Scholten, H., Beulens, A., Veenstra, T.: Integrating ICT applications for farm business collaboration processes using Fl Space. In: 2014 Annual SRII Global Conference, pp.232--240. IEEE (2014)

28.Oriade, C.A., Dillon, C.R.: Developments in biophysical and bioeconomic simulation of agricultural systems: a review. Agric. Econ. 17, 45--58 (1997)

29.Camarinha-Matos, L.M., Afsarmanesh, H.: Collaborative Networks. In: Wang, K., Kovacs, G.L., Wozny, M., Fang, M. (eds.) Knowledge Enterprise: Intelligent Strategies in Product Design, Manufacturing, and Management, vol. 207, pp. 26--40. Springer US (2006)

30.Prima Dania, W.A., Xing, K., Amer, Y.: Collaboration and sustainable agri-food supply chain: A literature review. MATEC Web Confer. 58 (2016)

31.Simatupang, T.M., Sridharan, R.: The collaborative index: a measure for supply chain collaboration. Int. J. Phys. Distrib. Logist. Manag. 35, 44--62 (2005)

32.Fischer, C., Hartmann, M., Reynolds, N., Leat, P., Revoredo-Giha, C., Henchion, M., Albisu, LM., Gracia, A.: Factors influencing contractual choice and sustainable relationships in European agri-food supply chains. Eur. Rev. Agric. Econ. 36, 541--569 (2009) 